\title{
Rural Voting in the 2004 Election
}

\author{
LAWRENCE HAMILTON
}

In the 2004 presidential election, rural voters tended to favor Republican George W. Bush, while urban residents more often voted for Democrat John Kerry, a pattern that became associated with the red state-blue state divide. A closer look at this rural-urban pattern finds many exceptions, however, highlighting the wide variety of places that compose rural as well as urban America. The character and politics of many rural places in the South, for example, are unlike those found elsewhere in the country. Similarly, unique rural places exist throughout the Northeast, Midwest, and West, each so unlike the others that the idea that there is one "rural America" breaks down-there are, in fact, several quite different rural Americas. This fact sheet presents detailed patterns of rural voting by region and "degree of ruralness" (population density). It also shows that these patterns are better explained by looking at demographic factors, such as ethnic composition and educational levels, than simply by where people live.

Republican George W. Bush defeated Democrat John Kerry in 2004 by 51 percent to 48 percent-a difference of some three million votes. Through the winner-take-all system of electoral votes, Bush received 286 votes to Kerry's 252. In the aftermath of the election, "red state/blue state" maps such as Figure 1 revealed a striking geographical pattern. Kerry had won blocks of states on the West Coast, in the Upper

Figure 1: States CASTING Electoral VOtes For BUSH (RED) OR KERRY (BLUE), IN THE 2004 PRESIDENTIAL ELECTION.

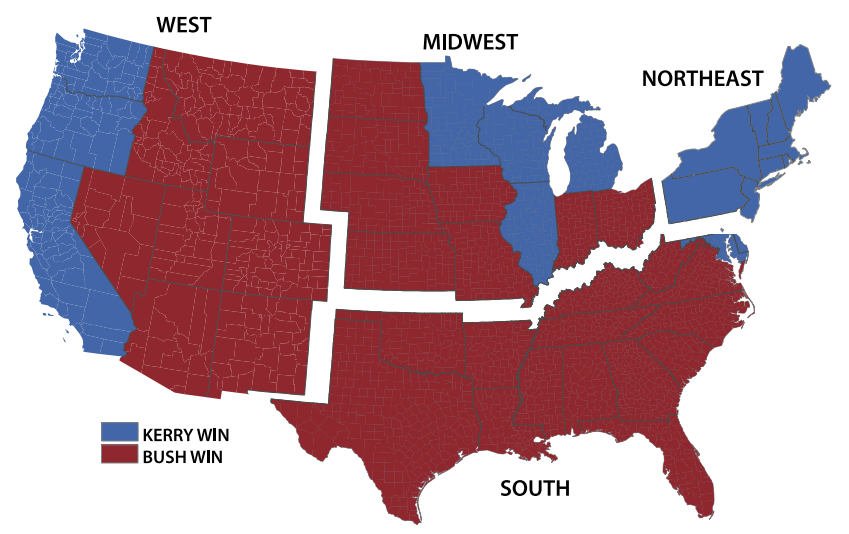

SOURCE: ROBINSON (2005)
Midwest, and the Northeast, while Bush won all the rest. The South presents an almost solid block of red states, as it had in the previous presidential election (Bush vs. Gore in 2000).

This simple picture of solid Democratic and Republican states becomes more complicated-and realistic-if we map election results by county rather than by state (Figure 2). All but a few states contain some mix of blue and red

Figure 2: Counties voting For BUSH (RED) OR Kerry (BLUE), IN THE 2004 PRESIDENTIAL ELECTION.

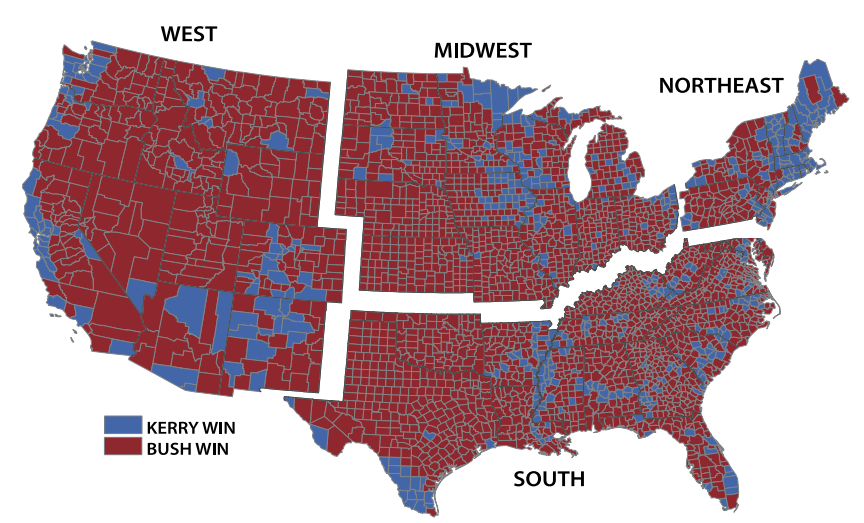

SOURCE: ROBINSON (2005)

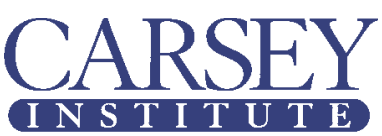

Building KNOWLEDGE FOR FAmilies AND Communities IN THE 21ST CENTURY
Huddleston Hall, 73 Main Street, Durham, NH 03824

(6o3) 862-2821 • www.carseyinstitute.unh.edu

The Carsey Institute Reports on Rural America are supported by the Annie E. Casey Foundation's initiative to strengthen rural families, Ford Foundation, and the W.K. Kellogg Foundation.
UNIVERSITY

of NEW HAMPSHIRE

Maps by Cliff Brown, University of New Hampshire. 
Figure 3: "Purple AmericA" MAP Showing the PROPORTIONATE VOTE FOR BUSH (RED) OR KERRY (BLUE) IN THE 2004 PRESIDENTIAL ELECTION.

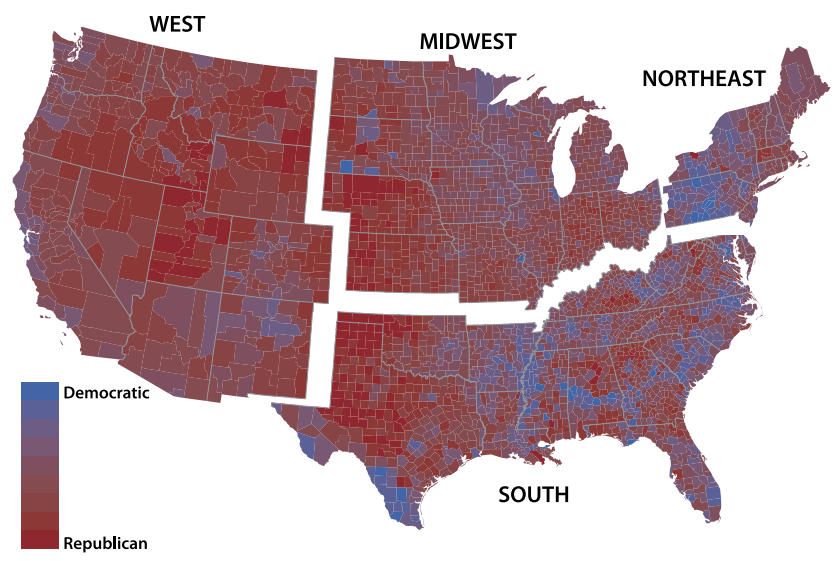

SOURCE: ROBINSON (2005)

counties. The predominant colors still follow broad regional schemes (more red than blue in the South, for instance), but other patterns now emerge as well. Most notable is the rural-urban dimension: the blue zones often mark cities and suburbs, while rural counties tend to be red. Exceptions to both the regional and the rural-urban patterns stand out in the South, where red states contain corridors of blue rural counties along the Mississippi River, in southern Texas, and across Alabama. These corridors suggest a third element to the geographic pattern of votes: race and ethnicity.

Although the crude red states/blue states map of Figure 1 accurately reflects the results of the U.S. electoral system, it hides the diversity of millions of voters in thousands of places, each place having many supporters of both parties. The more detailed map of Figure 2 hints at this diversity, but still colors each county as either red or blue. Therefore, a county voting 51 percent for Bush and another voting 99 percent for Bush will both appear equally red. The actual vote percentage in any one place falls somewhere in the range from 0 to 100 percent, and usually more toward the middle than extremes. "Purple America" maps such as Figure 3 represent vote percentages as shades from red to blue. The solid red look of the South and some Mountain states in Figure 1 becomes muted in this version, because even the red counties there contained large percentages of blue voters. On the other hand, a few states such as Utah and Nebraska remain nearly solid red because their voting was more uniformly Republican. In many parts of the country, the reddest areas are more rural, and also less ethnically diverse.

Moving from maps of state electoral results (Figure 1), to county results (Figure 2), to voting percentages (Figure 3 ), regional and rural-urban patterns become increasingly evident. Table 1 and Figure $\mathbf{4}$ carry this analysis further, breaking down vote percentages by region, and within region by metropolitan or rural counties. Each region has its own variations on the basic rural-urban pattern.
Table 1: Percent of votes going to candidates Kerry, BUSH AND NADER IN THE 2004 PRESIDENTIAL ELECTION, BY REGION AND METROPOLITAN/RURAL COUNTY TYPE IN THE 48 CONTIGUOUS STATES.

\begin{tabular}{llcc}
\hline $\begin{array}{l}\text { Census } \\
\text { region }\end{array}$ & Candidate & $\begin{array}{c}\text { Metropolitan } \\
\text { counties vote }\end{array}$ & $\begin{array}{c}\text { Rural } \\
\text { counties vote }\end{array}$ \\
\hline \multirow{2}{*}{ Northeast } & Kerry & $56 \%$ & $48 \%$ \\
& Bush & $43 \%$ & $50 \%$ \\
\multirow{3}{*}{ Midwest } & Nader & $1 \%$ & $1 \%$ \\
& Kerry & $51 \%$ & $41 \%$ \\
& Bush & $48 \%$ & $59 \%$ \\
\multirow{3}{*}{ South } & Nader & $<1 \%$ & $<1 \%$ \\
& Kerry & $45 \%$ & $40 \%$ \\
& Bush & $55 \%$ & $60 \%$ \\
\multirow{2}{*}{ West } & Nader & $<1 \%$ & $<1 \%$ \\
& Kerry & $53 \%$ & $38 \%$ \\
& Bush & $47 \%$ & $61 \%$ \\
& Nader & $<1 \%$ & $<1 \%$ \\
\hline
\end{tabular}

In the Northeast, Midwest, and West, a majority of metropolitan-county votes went for Kerry, whereas a majority of rural-county votes went for Bush. In the South, Kerry voting was stronger in the cities, but both metropolitan and rural counties favored Bush overall. The South appears most different from other regions in this respect.

Instead of categorizing counties in two groups, metropolitan or rural, it might be more realistic to view "ruralness" as a matter of degree. Population density, or the number of people per square mile, provides a rough but useful measure

Figure 4: Percentage of 2004 Vote going to Kerry AND BUSH, BY REGION AND METROPOLITAN OR RURAL COUNTY TYPE (48 STATES).
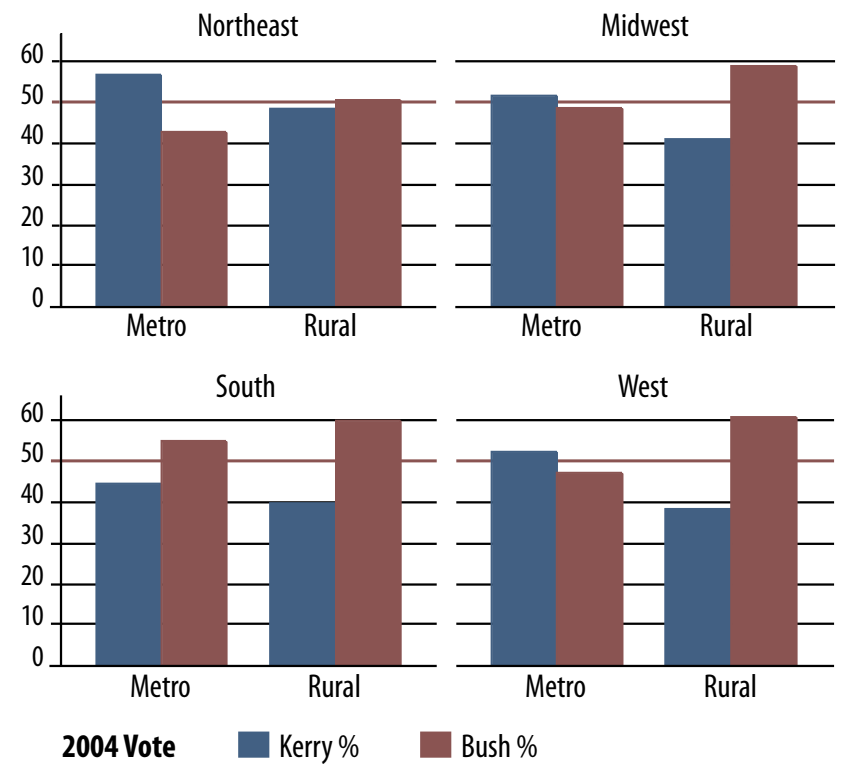
Figure 5: Percent votes Cast for Bush in the 2004 PRESIDENTIAL ELECTION VS. POPULATION DENSITY IN 3,054 COUNTIES OF THE 48 CONTIGUOUS STATES.

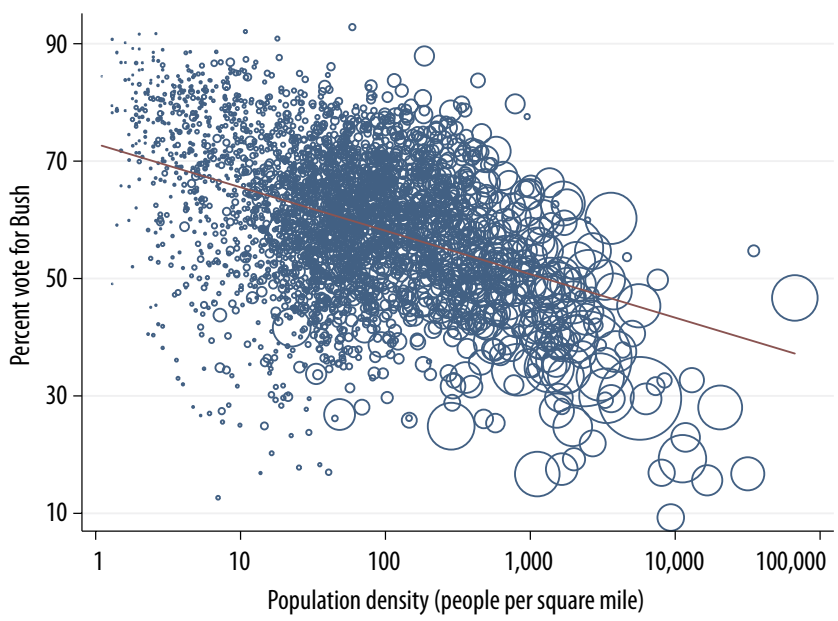

along these lines. Figure 5 visualizes the relation between percentage voting for Bush and population density as a scatter plot. Each circle in Figure 5 represents one of the more than 3,000 counties in the 48 contiguous states. The size (area) of each circle is proportional to the total number of votes cast. At upper left in this scatter plot are small circles representing small-population, low-density and pro-Bush counties. At lower right, conversely, are larger circles representing large-population, higher-density and pro-Kerry counties. The overall trend-percentage of Bush votes declines as population density rises-is summarized by a line slanting down left to right. This type of graph contains much more information than Figure 4, giving us a detailed view of the relation between voting and ruralness.

Figure 6 brings the regional dimension back in by drawing small scatter plots separately for the counties of each region. A general down-to-right trend, with more urban (denser) counties less favorable to Bush, can be seen within all four regional plots. In detail, however, each small plot has a distinct pattern reflecting the particular mix of counties in that region. The strongest rural-to-urban gradient in politics, or the steepest down-to-right line, occurs in the West. The weakest rural-to-urban gradient occurs in the South. Evident in the county maps of Figures 2 and 3 were corridors of proKerry rural counties within the overall pro-Bush states of the

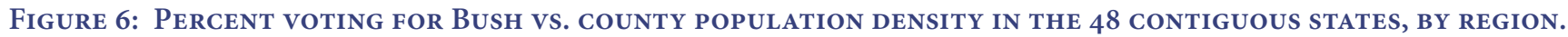
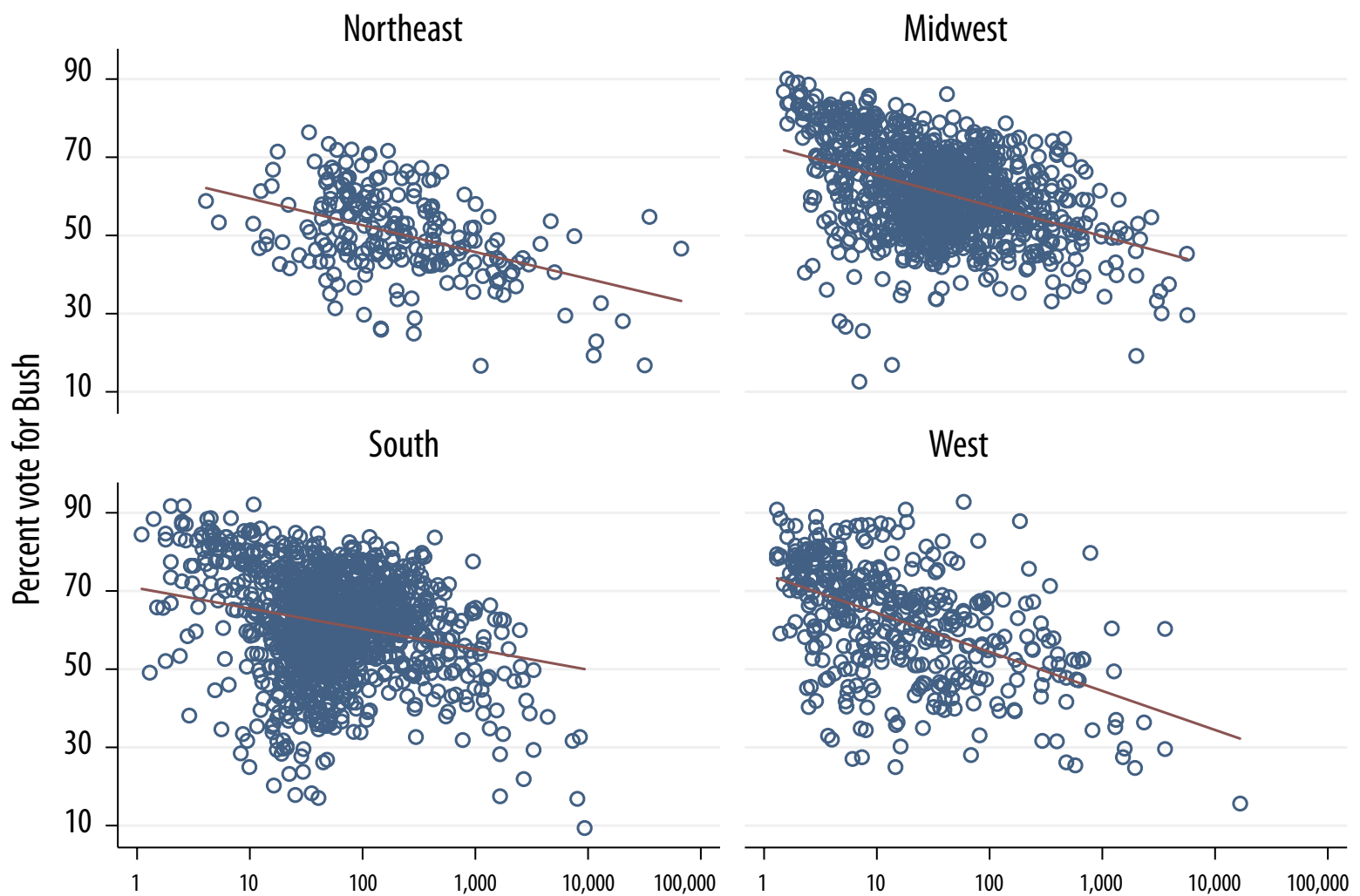

Population density (people per square mile) 
Figure 7: PERCENT VOTING FOR BUSH VS. COUNTY POPULATION DENSITY, With SYMBOLS MARKING COUNTIES THAT HAVE HIGH (OVER 30\%) PERCENTAGES OF PARTICULAR MINORITY GROUPS.

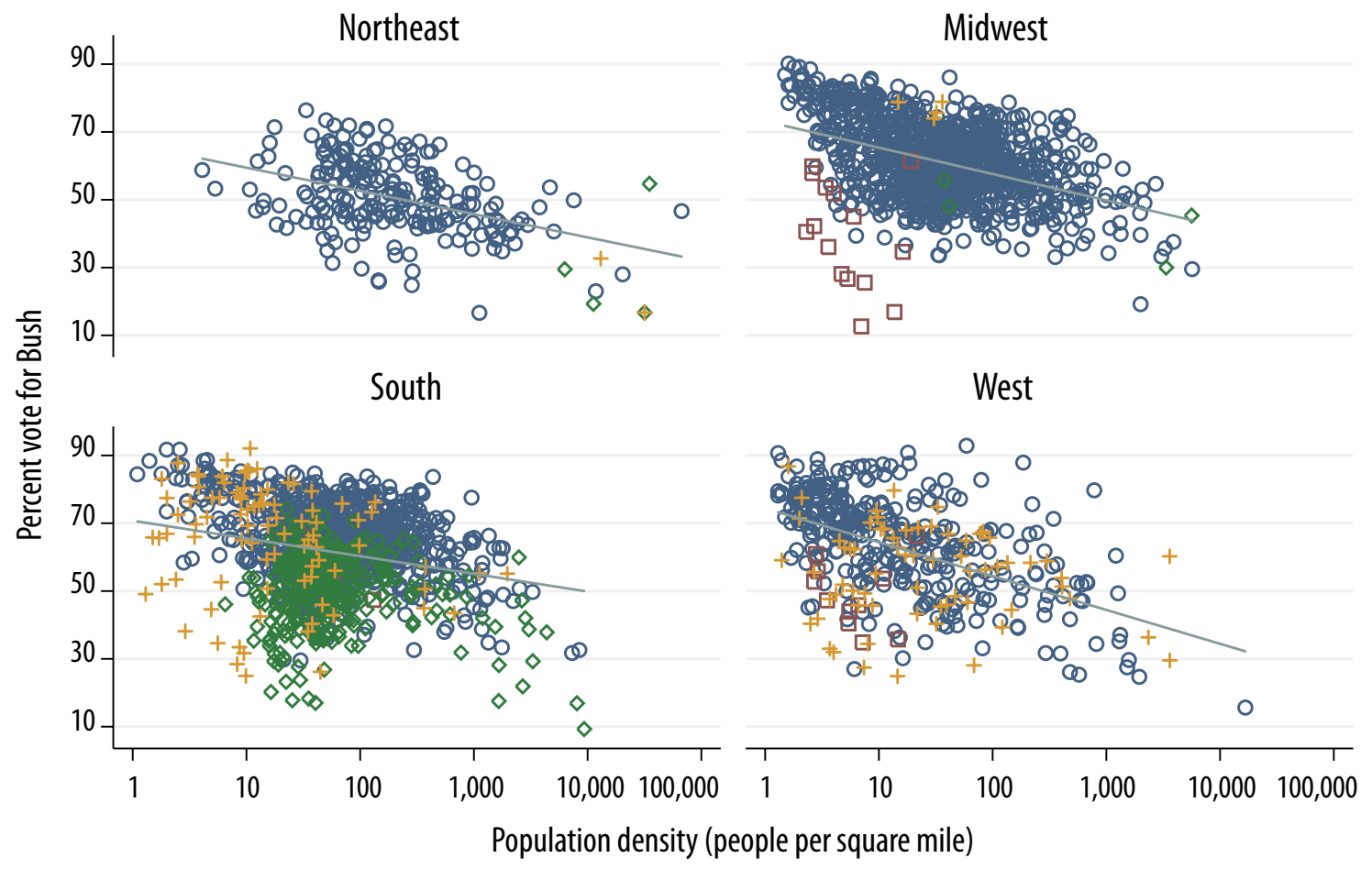

Black $>30 \% \quad+$ Hispanic $>30 \% \quad \square$ Native $>30 \% \quad$ OAll others

South. The same reality shows up in a new form in Figure 6 . Although lower-density (rural) counties generally tended to favor Bush, clusters of counties stand out in the lower left part of the South plot-places that had relatively low densities and yet voted strongly for Kerry. A few other counties stand similarly apart at lower left in the Midwest plot.

Figure 7 has the same layout, but contains additional information about the ethnic makeup of county populations. Different symbols mark counties where more than 30 percent of the population is black, Hispanic, or Native American. Some counties meet more than one of these criteria, in which case the symbols overprint; for example, the Bronx is 48 percent black and 36 percent Hispanic, seen at lower right in the Northeast plot. The ethnicity dimension illuminates some puzzling features of the regional patterns. In the Midwest, for example, the most rural counties-below 10 people per square mile-tended to favor Bush. We now see that the striking exceptions to this Midwestern pattern-low-density counties at lower left, which favored Kerry instead-are Indian reservations and other counties that have high percentages of Native Americans. Even in these tiny scatter plots, the South appears distinct from other regions. Only the South has a substantial rural black population, as evidenced by the many green diamonds representing counties at least 30 percent black, and with densities between 10 and 100 people per square mile.
The enlargement in Figure 8, which combines information on voting, density, size, and ethnicity of Southern counties, resolves the picture a bit further. The green diamonds again indicate counties where more than 30 percent of the population is black. In this figure, the area of each symbol represents the number of people voting in that county, which roughly corresponds to population size. Several large,

Figure 8: Percent voting for Bush vs. Population DENSITY, SOUTHERN COUNTIES ONLY. SyMBOL SIZES ARE PROPORTIONAL TO TOTAL VOTE IN 2004, AND SHAPES INDICATE ETHNIC COMPOSITION.

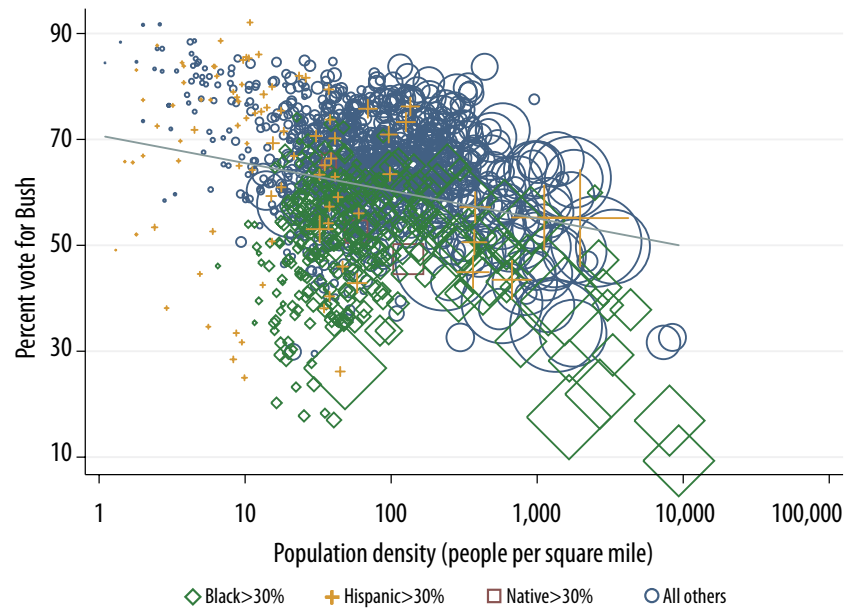


Figure 9: Percent voting for Bush vs. POPUlation DENSITY, NORTHEASTERN COUNTIES ONLY. SYMBOL SIZES ARE PROPORTIONAL TO TOTAL VOTE IN 2004, AND SHAPES INDICATE ETHNIC COMPOSITION.

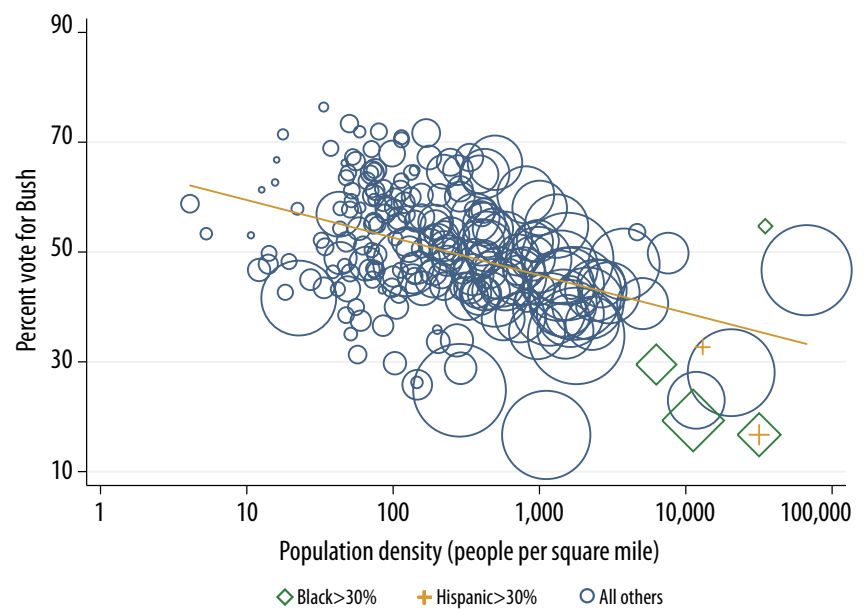

densely populated and pro-Kerry areas (including New Orleans, Baltimore, and Washington, DC) appear toward the lower right in this plot.

Toward upper left in Figure 8 are a scattering of small, low-density, and pro-Bush counties. These include several predominantly white rural areas (marked as blue circles) in Mississippi, Georgia, Alabama, and Florida. Also in this upper-left region, marked by orange + signs, are some small, low-density Texas counties that have populations at least 30 percent Hispanic, and that voted 60 percent or more for Bush. At lower left, in contrast, are some equally small, lowdensity, and substantially Hispanic Texan counties (orange + signs also) that voted heavily for Kerry. We have no way of knowing from these county-level data, of course, how Hispanics or the other ethnic groups within any county were voting.

At middling densities, between about 10 and 100 people per square mile, Figure 8 shows many small to mid-sized Southern counties that have substantial black populations-a pattern unique to the South. They include regions along the Mississippi River and in a belt across Alabama that formed conspicuously "blue" elements in maps of the otherwise red rural South (Figures 2 and 3). Historically, in the late 18th and 19th centuries, the labor needs of cotton growers in these regions helped drive the expansion of slavery. Today, the same regions still contain substantial black populations, many of whom live at or near the poverty line. Politically, both rural and urban counties with large black populations are more likely to vote Democratic.

If the South is the most ethnically diverse U.S. region, the Northeast is the least. Figure 9 focuses on Northeastern counties. The scatter plot follows the same symbol conventions as Figure 8, although there are no Northeastern
Figure 10: Percent voting For Bush vs. POPUlation DENSITY, MIDWESTERN COUNTIES ONLY. SyMBOL SIZES ARE PROPORTIONAL TO TOTAL VOTE IN 2004, AND SHAPES INDICATE ETHNIC COMPOSITION.

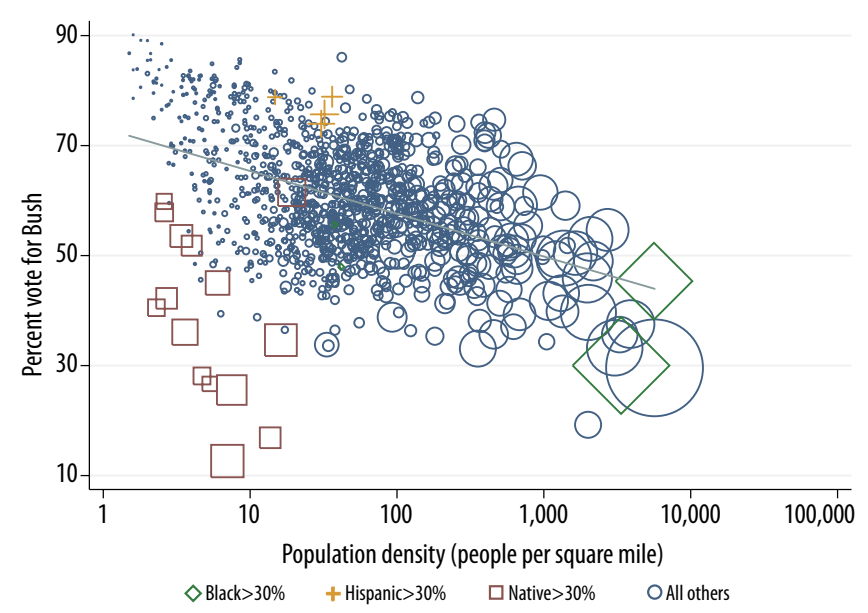

counties with more than 30 percent Native Americans. The higher-density cities tended to vote Democratic, whereas smaller and lower-density areas often voted Republican, in keeping with national trends.

Figure 10 repeats this analysis for Midwestern counties. Among the majority of Midwestern counties that do not have large minority populations (that is, the blue circles in this plot), the down-to-right drift is pronounced, indicating a strong pattern of more Democratic voting as density increases. Conversely, many low-density, low-minority counties in the Midwest voted quite strongly Republican, as did a few Kansas counties with substantial Hispanic populations (among the scatter at top left). The striking exceptions to this pattern are a cluster of very low-density, Democratic-voting counties at lower left in this graph, associated with Indian lands in the Dakotas, Montana, and Wisconsin.

Completing this region-by-region graphical tour, Figure 11 shows a similar scatter plot for the West. No Western counties are more than 30 percent black, but many have more than 30 percent Hispanic or Native American populations. Those with many Hispanics include Los Angeles and Denver, the large + signs at lower right, but also the more conservative Orange County, just above them. As in the Midwest, very low-density and low-minority counties tended to vote overwhelmingly Republican. The low-density Western counties also include some higher-minority, more Democratic areas with Native American (in New Mexico, Arizona and Montana) or Hispanic (New Mexico) populations.

Graphical displays such as these provide powerful tools for thinking about complex information. Figure 7, for example, visualizes more than 20,000 numbers. These graphs illustrate some of the ways that ethnic, regional, and rural- 
Figure 11: Percent voting for Bush vs. Population DENSITY, WESTERN COUNTIES ONLY (EXCEPT AlASKA AND HAWAII). SYMbol SIZES ARE PROPORTIONAL TO TOTAL VOTE IN 2004, AND SHAPES INDICATE ETHNIC COMPOSITION.

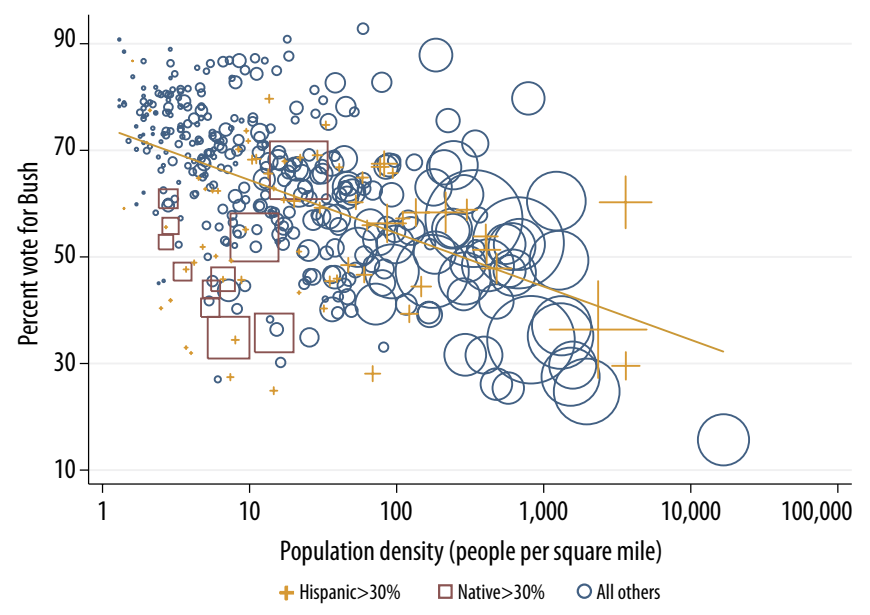

urban dimensions help explain detailed patterns in county vote results. To take still other dimensions into account, we need statistical tools such as regression analysis. ${ }^{1}$ With these we can ask, for example, whether voting patterns are systematic with respect not just to region, density and ethnic composition, but also to education levels, which many observers have portrayed as important. Like ethnicity, education overlaps somewhat with the urban-rural dimension. The percentage of college graduates, for instance, tends to be higher in cities. Regression can help to untangle the individual effects of such overlapping dimensions. A region-by-region analysis, asking how the percentage of Bush votes could be predicted from county population density, percentage black, percentage Hispanic, and percentage college educated yields both expected and unexpected results. It turns out that these four characteristics explain between 21 percent and 41 percent of the variation in 2004 voting within each region of the country.

The descriptions below refer to net effects, each calculated after adjusting for the other three factors.

- Percentage college educated-In the Northeast and West, counties with higher percentages of college graduates tended to give fewer votes to Bush. Indeed, this is the strongest single predictor of Bush (or Kerry) votes for those regions. In the South, education had a weaker and opposite effect: Counties with more graduates tended to give more votes to Bush. In the Midwest, education had no apparent effect.

\footnotetext{
${ }^{1}$ Regression analysis is widely used by researchers to study relationships among quantitative variables. For example, it allows us to estimate the influence of percent college education on percent voting for Bush, while adjusting for other factors such as population density and ethnic composition.
}

- Percentage black-Consistently across the Northeast, Midwest, and South, the higher the percentage of black residents, the lower the Bush vote tended to be. A similar pattern, although not statistically significant, appears among Western counties.

- Percentage Hispanic-This dimension had inconsistent effects. In the Northeast, South, and West, the percentage voting for Bush tended to decline as percentage Hispanic increased. In the Midwest, however, Bush votes increased with the percentage Hispanic.

- Population density-Even after adjusting for ethnicity, education, and region, population density remains a significant predictor of votes in the Midwest, South and West. Higher-density counties gave proportionately fewer votes to Bush. In the Northeast, density proved to have little net effect, once we adjust for the stronger impact of education levels.

\section{Conclusions}

Underneath the striking simplicity of red state/blue state maps we find a more complicated but still geographically connected pattern. Electoral College outcomes in part reflect variations in the educational and ethnic composition of regional populations. Counties with higher percentages of blacks tended to give higher percentages of their votes to Kerry. Counties with higher percentages of college graduates tended to give more votes to Kerry in the Northeast and West, but not so in the Midwest and South where racial voting patterns appeared more dominant.

In general, rural areas tended to vote more Republican, but with prominent exceptions of some rural minority areas-Native American lands in the Midwest and West, and black farming regions in the South. Hispanic populations had a less distinct impact on voting, probably reflecting both more divergent voting, and a substantial fraction unable to vote if they are not citizens or registered voters. The rural-urban effects remain prominent, however, even after we statistically adjust for differences in region, ethnicity and education.

Geographical patterns in the proportion black, Hispanic, or Native American arise from complex regional histories that extend back two centuries or more. Patterns in education and population density reflect more recent shifts as well. Strong trends in rural-urban, interregional, and international migration can be expected to shift population compositions and hence political balances in the future.

\section{References}

Robinson, Anthony (2005). “Geovisualization of the 2004 Presidential Election." Available at -www.personal.psu.edu/ users/a/c/acr181/election.html 